\title{
A reliable early symptom of bronchial or tracheal rupture
}

\author{
A. EIJGELAAR, J. N. HOMAN VAN DER HEIDE \\ Department of Thoracic Surgery, Surgical Clinic, State University, Groningen, \\ The Netherlands
}

\begin{abstract}
A tracheal or bronchial rupture is a severe lesion which is frequently overlooked during the initial post-traumatic period. The best results in the treatment of such ruptures are obtained by the earliest possible restoration of the continuity of the air passages. Early reconstruction, however, depends on early diagnosis. The diagnosis is established with certainty by means of bronchoscopy. The symptom of 'deep cervical emphysema' is presented as an aid in selecting, from the many accident victims with chest injuries, those who should be submitted to bronchoscopy for immediate identification of any rupture of the major air passages. This deep cervical emphysema is readily recognizable on an antero-posterior radiograph of the cervical region and upper mediastinum.
\end{abstract}

With the advancing mechanization and ever growing density of traffic, the number of patients with severe thoracic lesions is still increasing. In a small proportion of these patients the injury causes a rupture of the tracheobronchial tree. The true nature of this lesion is often misunderstood. at least in the first instance (Larizadeh, 1966).

In a survey of the literature on 167 cases of traumatic bronchial rupture, Burke (1962) concluded that in a large proportion of these patients $(69 \%)$ the injury was not diagnosed until the stenosis that follows bronchial rupture called attention to itself through atelectasis or sepsis.

Indirect efforts as well as bronchial reconstructions have been undertaken to relieve the effects of post-traumatic stenoses of the larger air passages. Although later reconstruction resulted in satisfactory lung-physiological data in several cases (Razemon and Gernez-Rieux, 1956; Mahaffey, Creech, Boren, and DeBakey, 1956 ; Tyson, Watson, and Sibley, 1958), it is evident that uniform results cannot be expected from these procedures (Chesterman and Satsangi, 1966). Immediate restoration of the continuity of the bronchus at the time of injury is therefore generally accepted as the method of choice in the treatment of a ruptured tracheobronchial tree (Dor, Forster, and le Brigand, 1964).

Early reconstruction, however, depends on early diagnosis. In many publications and in textbooks on the diagnosis of tracheobronchial rupture (Hamilton Bailey, 1958; Cooper, 1964;
d'Abreu, 1965 ; Irmer, Baumgartl, Grewe, an Zindler, 1967), it is emphasized that patients wit severe thoracic injuries should be submitted to bronchoscopy if a bronchial rupture is to be diagnosed quickly and with certainty.

The indications for bronchoscopy in thes patients are (a) pneumothorax, sometimes tensiog pneumothorax, especially when the lung remains collapsed in spite of catheter drainage of the pleural space; and (b) pneumomediastinum.

When, in a case of pneumothorax, the lung expands insufficiently following drainage of the pleural space, it is evident that severe air leakage. exists, possibly as a result of a bronchial rupture According to Burke (1962), the pneumothorax in cases of bronchial rupture often shows a favoug able response to drainage. Due to the apparentlo good result of treatment of the pneumothorax i⿱ these cases, bronchoscopy is omitted, at least ino the first instance: the bronchial rupture remains undiagnosed.

Pneumomediastinum, too, is frequently oveto looked because it is difficult to identify this ap normality in an antero-posterior chest radie graph, especially when there is not extensive accumulation of air in the mediastinum (Ozonoff 1964).

When the above indications for bronchoscop in patients with chest injuries are adhered to iro tervention is frequently omitted, so that bronchig rupture is not diagnosed immediately after the accident. 


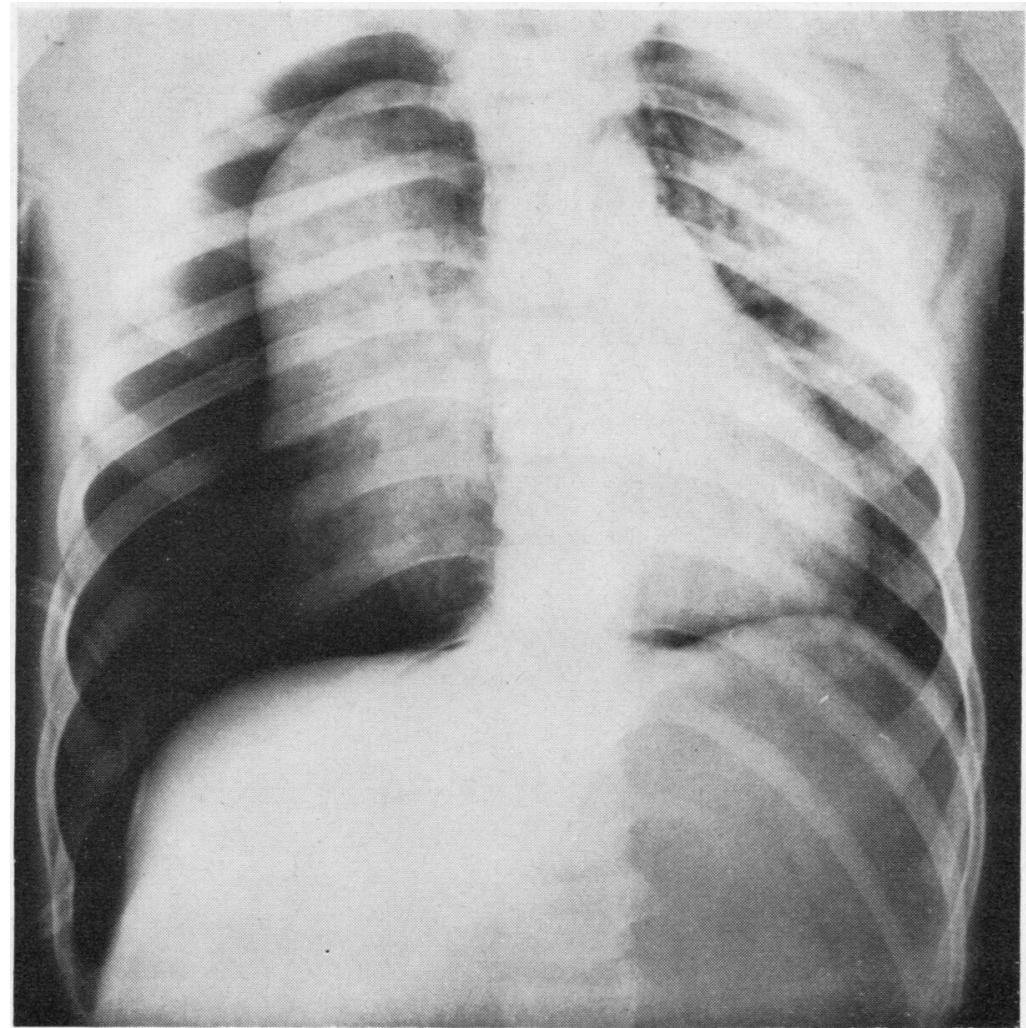

FIG. 1. Case 1. Chest radiograph of a 9-year-old boy with a bronchial rupture, a few hours after the accident.

The case histories of two of our patients illustrate the varying and uncertain prognosis of a bronchial rupture which is not presented for operation until some time after the accident.

\section{CASE REPORTS}

CASE 1 A healthy 9-year-old boy was hit by a car on 17 July 1965. On admission he had a tension pneumothorax on the right side (Fig. 1). A pleural suction drain was applied, and the lung expanded well. A chest radiograph, obtained nine days after the accident, was satisfactory, and the pneumothorax was considered to have been adequately treated. The drain was removed.

Sixteen days after removal of the drain the right lung was found to have collapsed completely. The patient was then transferred to the Groningen Surgical Clinic.

There was total obstruction of the right main bronchus immediately beyond the carina. The stenotic portion of the bronchus was excised on 18 August, and an end-to-end anastomosis was established. Although the immediate post-operative result was good, stenosis of the anastomosis occurred some time later. This favoured the occurrence of recurrent pneumonia, and ultimately the only remaining choice was pneumonectomy, which was performed on 29 November 1965 . The boy has since done well but there is unmistakable exertional dyspnoea.

It is rather sad to know that this pneumonectomy could have been avoided if the bronchial rupture had been diagnosed in time.

CASE 2 A healthy 18-year-old girl was admitted to a local hospital on 14 October 1967 after a moped accident. She had a right-sided pneumothorax (Fig. 2). On 17 October she became dyspnoeic when tension pneumothorax occurred. A pleural suction drain was introduced through the second right intercostal space.

In spite of the drainage the lung failed to expand sufficiently. On 26 October (12 days after the accident) bronchial rupture was diagnosed on the basis of bronchoscopy, and the patient was transferred to the Groningen Surgical Clinic.

On 27 October the right main bronchus, which showed a total rupture, was reconstructed by means of an end-to-end anastomosis. The post-operative course was uneventful and the anastomosis healed 


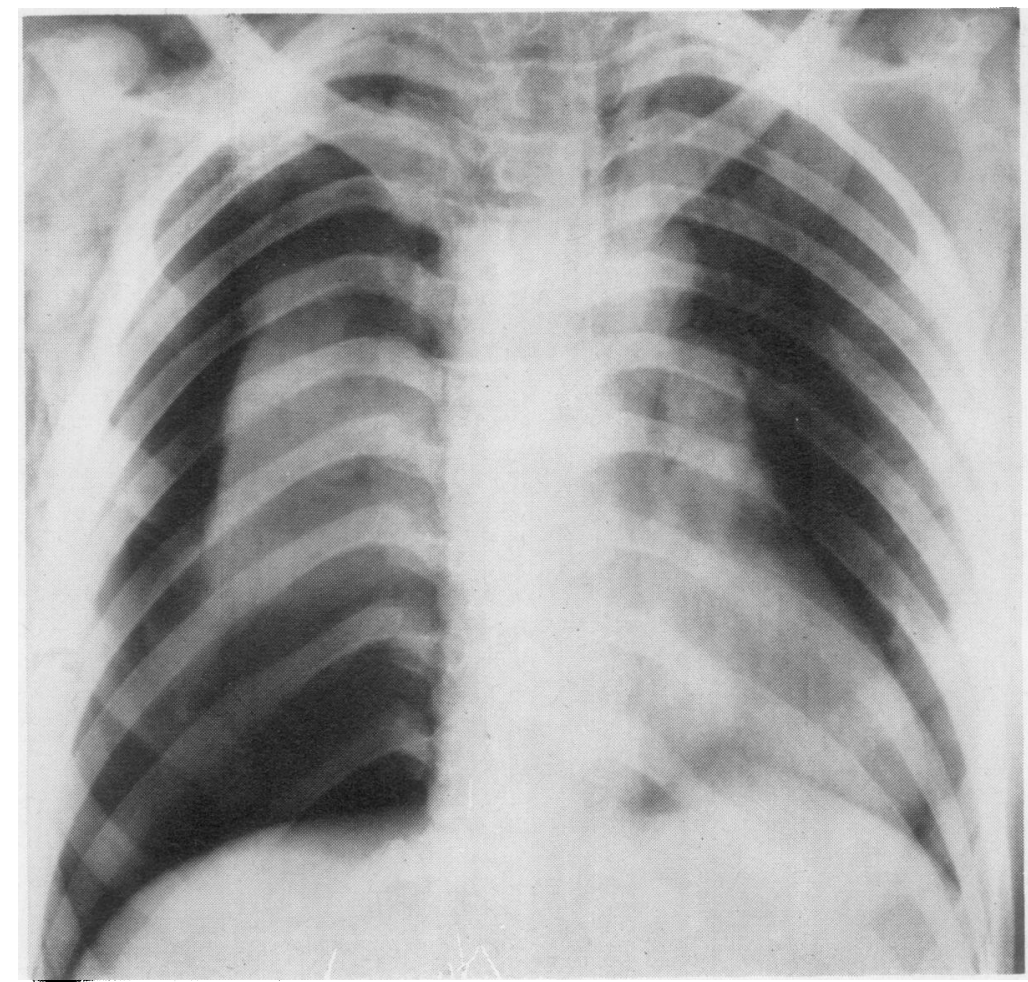

FIG. 2. Case 2. Chest radiograph of an 18-year-old girl with a bronchial rupture, a few hours after the accident.

well. After 18 months lung function proved to be virtually normal (Eijgelaar, in preparation).

Our experience with these two patients raised the question whether the diagnosis could have been established earlier. To answer this question we reviewed the chest radiographs of these patients and also of five others treated for bronchial rupture in the Groningen Surgical Clinic since 1952.

In six of these seven patients the radiographs revealed abnormalities on which a near-certain diagnosis of bronchial rupture could have been based if the significance of these features had been understood.

In these six cases we found that even the first chest radiograph (made within a few hours of the accident) disclosed the unmistakable features of air accumulation (emphysema) in the tissues of the cervical region (Figs 3 and 4). This air accumulation was localized in the deeper interstices of the cervical tissue, and not only in the subcutaneous tissue.

\section{DISCUSSION}

According to Burke (1962), pneumothorax occurs in at least $70 \%$ of cases of bronchial rupture (Fig. 5). It is possible that a rupture of the majos air passages occurs without any lesion of thes parietal pleura, and therefore without pneumo? thorax (Fig. 6).

With or without pneumothorax, a tear in the larger air passages always causes accumulation of air in the mediastinum. The air in the median stinum is subject to some tension and seeks tou escape. It finds this escape to, among other partse the cervical region, first of all into the deeper interstices and finally into the subcutaneous tissue of the cervical region (Evans and Smalldon, 1950) $\$$

The air enters the deeper interstices of the cer: vical region easily and quickly because the spacs within the fascia colli media is the anatomica extension of the mediastinum. In this area the ai travels easily to the cervical region along the large vessels and the trachea. 


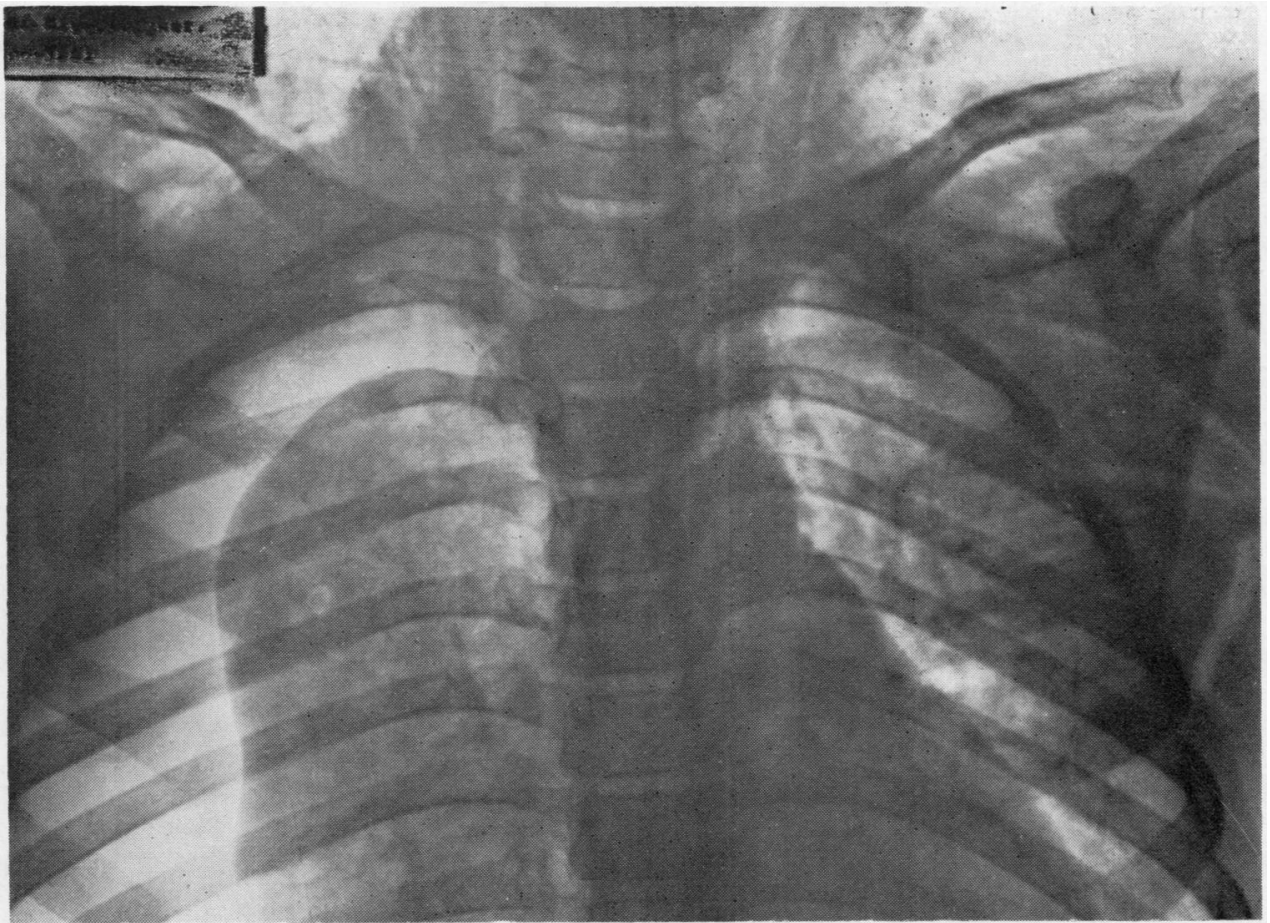

FIG. 3. Case 1. Detail of the upper mediastinum and part of the cervical region.

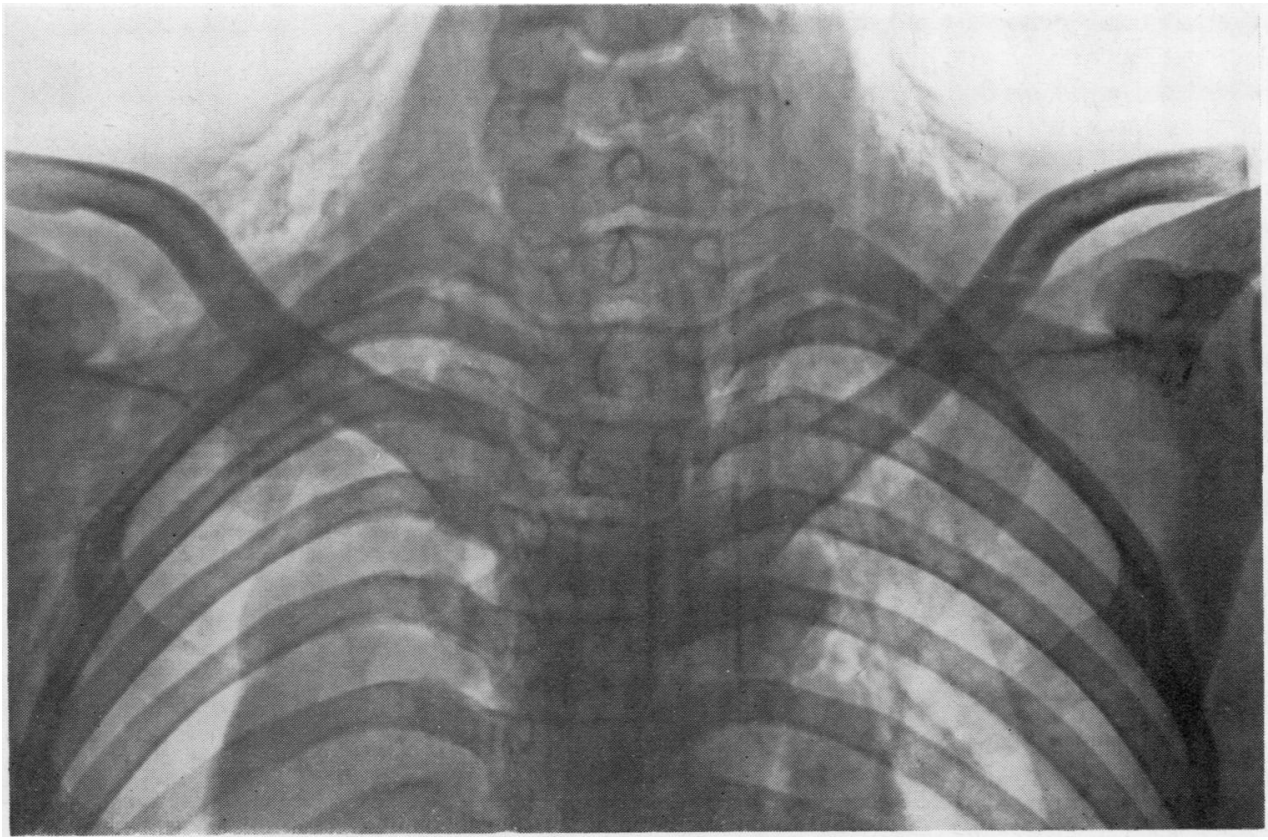

FIG. 4. Case 2. Detail of the upper mediastinum and part of the cervical region. 


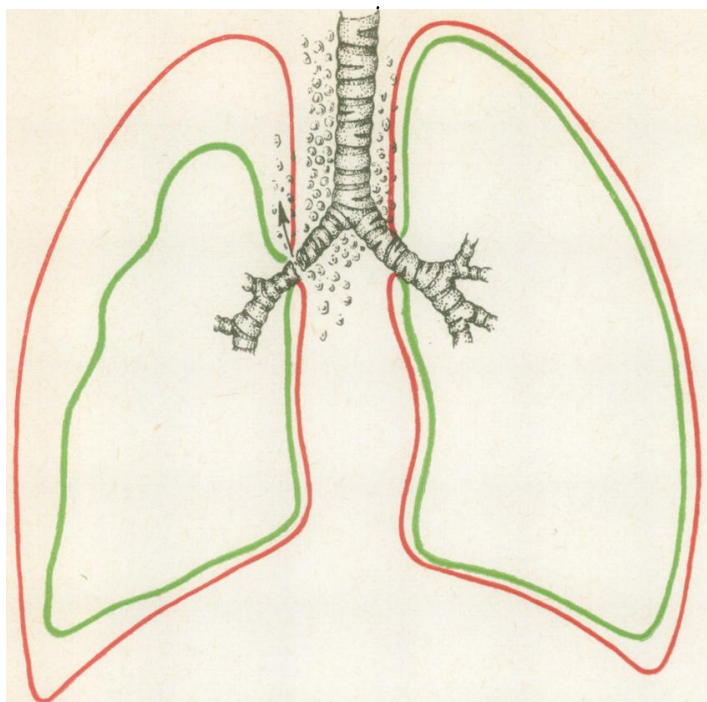

FIG. 5. Diagram showing a bronchial rupture with pneumothorax.

This accumulation of air within the fascia colli media is here called 'deep cervical emphysema' to differentiate it from the subcutaneous cervical emphysema, which is localized outside the fascia colli media. The deep cervical emphysema cannot be detected by palpation. Only in a later stage does this air escape to the subcutaneous cervical tissue (Lillard and Allen, 1965).

The fact that the deep cervical emphysema was visible on radiographs made within a few hours of the accident in six of the seven patients shows that this phenomenon is a reliable early symptom in the diagnosis of tracheobronchial rupture.

It should be emphasized that the symptom is clearly visible only on radiographs of the cervical region and upper mediastinum.

As a rule, only a chest radiograph is made in cases of thoracic injury. If this chest radiograph is directed accurately, it does not include the regiones colli, and consequently the deep cervical emphysema which results from accumulation of air in the mediastinum is not detected.

In addition to a chest radiograph another should be made of the upper mediastinum and the cervical region if the features of deep cervical emphysema are to be clearly seen. In a patient with a thoracic injury, this symptom denotes unmistakable air leakage to the mediastinum, and it is in these patients that bronchoscopy is justified and indicated.

The value of the symptom of 'deep cervical emphysema' is illustrated by the following case history.

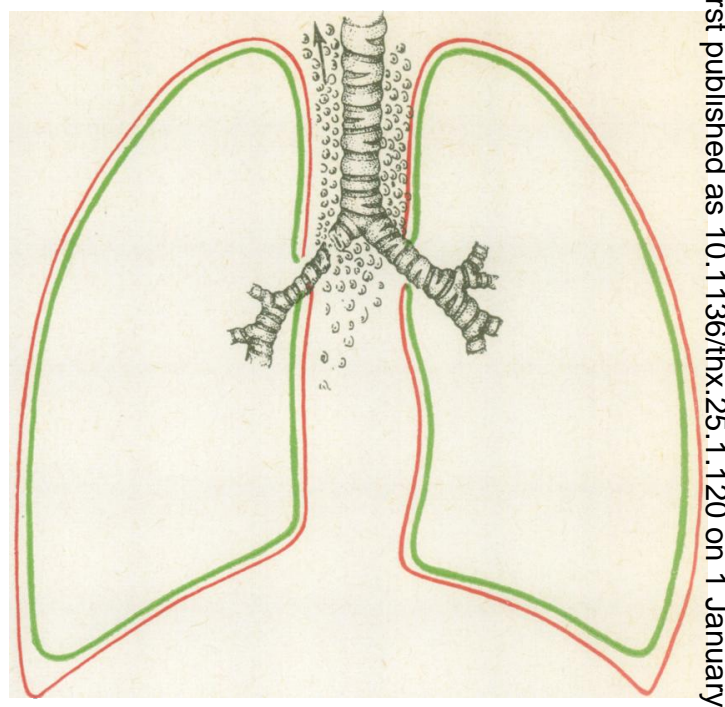

FIG. 6. Diagram showing a bronchial rupture without $\overrightarrow{0}$ pneumothorax.

CASE 3 A 29-year-old man was seen at the outpatient clinic a few hours after sustaining a chest $\sum^{2}$ injury. He showed marked dyspnoea and mild cyanosis. The chest radiograph disclosed fractures of the 5th, 6th, and 7th left ribs at the level of the posterior axillary line. There were no other radio- $\varrho$ logical changes. An antero-posterior radiograph of $\overrightarrow{\vec{O}}$ the cervical region revealed an accumulation of air 3

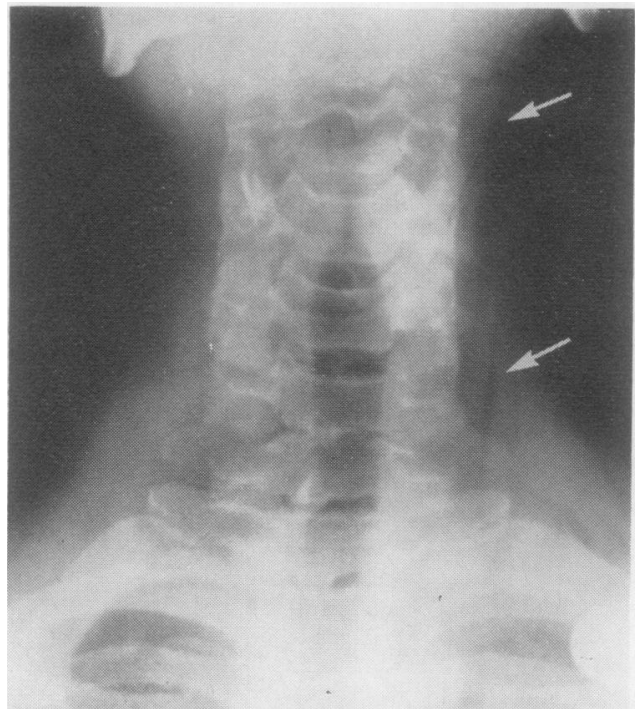

FIG. 7. Unilateral 'deep cervical emphysema' in a patient $\frac{\Omega}{\Phi}$ with a small tear in the bronchus to the mediobasal segment of the left lower lobe. 
within the fascia colli media, along the sternocleidomastoideus muscle (Fig. 7). Bronchoscopy disclosed a small tear in the mucosa of one of the basal segments of the left lower lobe. This bronchial tear required no surgical treatment but did cause unequivocal emphysema within the fascia colli media.

Since 'deep cervical emphysema' is a direct consequence of a pneumomediastinum, it is not a specific symptom of bronchial rupture. Its features occur in association with any accumulation of air in the mediastinum, e.g., in oesophageal perforation or perforation of an emphysematous bulla within the visceral pleura.

However, deep cervical emphysema seems a reliable criterion for selecting from a large number of patients with chest injuries those who require bronchoscopy for early diagnosis of a possible bronchial lesion.

\section{SUMMARY}

A follow-up study of seven patients with bronchial rupture disclosed in six patients an early spread of a pneumomediastinum to the cervical region along the trachea and large vessels within the fascia colli media: a deep cervical emphysema. This emphysema formed within a few hours of the occurrence of the bronchial rupture.

The unmistakable features of this deep cervical emphysema are easily recognized on a plain antero-posterior radiograph of the upper mediastinum and neck, and this seems to be a reliable early symptom of bronchial rupture.
In patients with severe chest injuries, the indication for bronchoscopy is, in our opinion, determined chiefly by the radiographic features of the cervical region, and to a lesser extent by the chest film. In such patients a separate radiograph of the upper mediastinum and the cervical region should be made in addition to the chest film. On the basis of the radiographic features of the cervical region it is easy to establish whether immediate bronchoscopy is justified and indicated to ensure early and certain diagnosis of a rupture of the tracheobronchial tree.

\section{REFERENCES}

d'Abreu, A. L. (1965). Thorax [Clinical Surgery, ed. Rob, C. G., and Smith, R., Vol. 5], p. 11. Butterworths, London.

Bailey, H. Hamilton (1958). Emergency Surgery, 7th ed. Wright, Bristol.

Burke, J. F. (1962). Early diagnosis of traumatic rupture of the bronchus. J. Amer. med. Ass., 181, 682.

Chesterman, J. T., and Satsangi, P. N. (1966). Rupture of the trachea and bronchi by closed chest injury. Thorax, $21,21$.

Cooper, P. (1964). The Craft of Surgery. J. and A. Churchill, London.

Dor, J., Forster, E., and le Brigand, H. (1964). Ruptures Traumatiques des Bronches et de la Trachóe Thoracique. Doin, Paris.

Evans, J. A., and Smalldon, T. R. (1950). Mediastinal emphysema. Amer. J. Roentgenol., 64, 375.

Irmer, W., Baumgartl, F., Grewe, H. E., and Zindler, M. (1967). Dringliche Thoraxchirurgie. Springer-Verlag, Berlin.

Larizadeh, R. (1966). Rupture of the bronchus. Thorax, 21, 28.

Lillard, R. L., and Allen, R. Parker (1965). The extrapleural air sign in pneumomediastinum. Radiology, 85, 1093.

Mahaffey, D. E., Creech, O., Jr., Boren, H. G., and DeBakey, M. E. (1956). Traumatic rupture of the left-main bronchus successfully repaired eleven years after injury. J. thorac. Surg., 32, 312.

Ozonoff, M. B. (1964). Injury to the respiratory tree. Calif. Med., $100,14$.

Razemon, P., and Gernez-Rieux, Ch. (1956). Rupture de la bronche souche gauche datant de quinze mois. Resection-anastomose suivie de récupération fonctionnelle du poumon. Mém. Acad. Chir., 82, 724.

Tyson, M. D., Watson, T. R., and Sibley, J. R. (1958). Traumatic bronchial rupture with plastic repair. New Eng!.J. Med., 258, 160. 